\title{
Lake water level variations in Belarus
}

\author{
Aleksandr A. Volchak ${ }^{1}$, Ivan Kirvel ${ }^{2}$ \\ ${ }^{1}$ Brest State Technical University, Moskovskaya 267, 224017 Brest, Belarus, e-mail: volchak@tut.by \\ ${ }^{2}$ Pomeranian University in Słupsk, Partyzantów 27, 76-200 Slupsk, Poland, e-mail: kirviel@yandex.by (corresponding author)
}

\begin{abstract}
Lake level is one of the most important lake characteristics which allows the results of different effects to be identified and detected. In this work time series of the water levels of Belorussian lakes were analysed in order to detect pattern variations, to evaluate quantitatively the transformation of the hydrological regime of lake ecosystems and to develop prediction models. The possibility of plotting predicting models of lake water levels one year in advance was shown. The complication in plotting predicting models is in its individuality, the huge volume of initial data and the impossibility of immediate assessment of the results. Additional complications are caused by the inhomogeneity of time series of water levels in lakes.
\end{abstract}

Key words: lakes, lake water level, hydrological regime, prediction models

\section{Introduction}

Lakes are unique water bodies that have important economic and environmental meaning. There are around 10,000 lakes in Belarus having a total water surface area of $2000 \mathrm{~km}^{2}$ and a total water volume of 6-7 $\mathrm{km}^{3}$. Lakes accumulate clean fresh water and have the function of regulating surface and ground waters. The fact that water exchange is slower in lakes means that they are more vulnerable than rivers and can be sensitive indicators of many climate change factors. Recently nature and climate factors as well as anthropogenic influence caused hydrological regime changes in Belorussian lakes, sometimes significant. That is why there is a need for environmental prediction considering climate change and anthropogenic impact, which points to a number of goals in research on the evolution of lake ecosystems, quantitative and qualitative diagnostics, and the development of imitative and predictive models.

A significant difficulty in modelling the timerelated hydrological regime of lakes is a lack of data for retrospective analysis. Increasing anthropogenic impact on water ecosystems, and difficulties in separating natural and anthropogenic components in the processes observed make this aim even more problematic. Water regime formation is individual and needs careful consideration in each case. Lake level is one of the most important lake characteristics which allows results of different effects to be identified and detected. Besides, level regime data are useful for a number of hydrological and water management goals.

The aim of this work is to analyse time series of the water levels of Belorussian lakes in order to detect pattern variations, to evaluate quantitatively the transformation of the hydrological regime of lake ecosystems and to develop prediction models.

\section{Materials and methods}

For this research hydrometeorological service experimental data of long-term water level observations from the 9 largest Belorussian lakes were used. Research objects are lakes that have a great value for environmental protection and the national economy and are placed in Belorussian Poozerskaya and Polesskaja (Lake Chervonoe) provinces. The surface areas of the lakes are from 3.13 (Senno) to $79.62 \mathrm{~km}^{2}$ (Naroch), with the volume of the water from 26.83 to $710 \mathrm{hm}^{3}$, respectively. Lakes are classified as shallow (maximum depth Lake Vygonochanskoe - 2.3 m, Lake Nesherdo - $8.1 \mathrm{~m}$ ), medium deep (Lake Lukomlskoe - 11.5 m, Naroch - $24.8 \mathrm{~m}$ ) and deep (Lake Senno $31.5 \mathrm{~m}$ ). All lakes are closely connected to the hydro- 
graphic network. The surface areas of the catchments are from $61.1 \mathrm{~km}^{2}$ (Lake Vygonochanskoe) to $423 \mathrm{~km}^{2}$ (Lake Driviaty), and of the specific catchments from 0.046 (Lake Senno) to 0.42 (Lake Vygonochanskoe), with an average value for the investigated lakes of 0.2. All lakes have slow water exchange, and the specific water exchange index $\left(\mathrm{V}_{\text {lake }} / \mathrm{V}_{\text {inflow }}\right)$ is from 0.15 (Lake Lukomskoe) to 1.9 (Lake Senno), with an extremely low value representing Lake Naroch - 14.9.

The annual change in the lake level is typical for temperate climate lakes. The amplitude of the longterm change in the lake level varies for years with different humidity from 0.29 (Lake Miastro) to 0.86 (Lake Neshedro) with the average value being $0.67 \mathrm{~m}$. The high value for the amplitude of the level of Lake Osvejskoe $(1.07 \mathrm{~m})$ is due to anthropogenic impact. Lake basin morphometric qualities which influence the size of the increase in water level are the presence of a distinct slightly sloping shallow zone (littoral), slightly sloping slopes and developed bottomland (except Lake Senno).

Factors influencing the formation of a level regime can be divided into two groups. The first group represents global factors relating to large territories, while the second represents local factors. The level of water in a lake can be represented as follows:

$$
H(t)=H_{b}(t) \pm \Delta H_{l}(t)
$$

$H(t)$ - water level in the current calendar year [cm]; $H_{b}(t)$ - component determining the formation of the water level of background lakes $[\mathrm{cm}] ; \pm \Delta H_{l}(t)$ - impact of factors determining the formation of the local water level [cm].

The influence of global factors on the formation of lakes' level regime can be described as a linear or polynomial second degree trend, being precise enough for practical calculations:

$$
\begin{aligned}
& H_{f}(t)=H_{f}(0) \pm \Delta H \cdot t ; \\
& H_{f}(t)=\alpha \cdot t^{2}+\alpha \cdot t+\gamma ;
\end{aligned}
$$

$H_{f}(0)$ - lake level at the beginning of the period considered $[\mathrm{cm}] ; \Delta H$ - water level change rate $[\mathrm{cm}$ $\left.\mathrm{yr}^{-1}\right] ; \alpha, \beta, \gamma$ - empiric coefficients; $t$ - calendar year.

The level change rate of lakes is defined as the first derivative of the level change regime function. For equation (2) the level change rate is a constant and is equal to the regression coefficient. Describing the dynamics of lakes' water level fluctuations which diverge from the linear, the level regime change rate is a variable and is defined as follows:

$$
\Delta H(t)=2 \cdot \alpha \cdot t \pm \beta
$$

Equations (2-3) describe the background component of the formation of the level regime, where the difference between the actual water level and the background component represents deviations that are due to weather fluctuations and changes in local factors.

Dynamics of the formation of the local component of lakes' water level regime can be described as an additive function:

$$
\Delta H_{l}(t)=H_{u}(t) \pm H_{\eta}(t)
$$

$H_{u}(t)$ - deterministic function, $H_{\eta}(t)-$ random component.

Function $H_{u}(t)$ can often be chosen in such a way that process $H_{\eta}(t)$ is much simpler than $\Delta H_{l}(t)$ and then solving problems associated with named processes is significantly simplified.

For stationary process detection of regularities in water level formation (slow increase or decrease monotonous trend; periodical changes - cyclic trend; constancy in some periods of time with rapid changes between periods - stage trend) is a process of practical interest. All these situations may be described by polynomial trend approximation (Ismaiylov and $\mathrm{Fe}$ dorov 2001):

$$
H_{u}(t)=a_{0}+\sum_{i=1}^{k} a_{i} \cdot \varphi_{i}(t)
$$

$\varphi_{i}(t) \ldots \varphi_{k}(t)$ - given time functions; $a_{0} \ldots a_{k}-$ regression coefficients.

Time functions may be linear, power, exponential or logarithmic if the trend is monotonous, or trigonometric if the trend is cyclic, or piecewise constant if the trend is stage. In all such cases parameters $a_{0} \ldots$ $a_{k}$ are evaluated according to the number of observations H1...Hn.

If the trend is not defined, sample autocorrelation (SAF) and partial autocorrelation (PAF) functions should be considered together for the given process, and changes in annual runoff can be defined with the help of these functions. Further criteria should be used for the evaluation of the degree of non-stationarity of 
the process and model choice (Ismaiylov and Fedorov 2001; Boks and Dzhenkins 1974) (Table 1).

The impact of the random component on level regime formation can be defined as follows:

$$
H_{\eta}\left(P_{\%}\right)=\bar{H}_{\eta}\left(F_{P_{\%_{0}}} \cdot C_{v}+1\right) \text {, }
$$

$\bar{H}_{\eta}$ - average value of the random component of water surface level $[\mathrm{cm}] ; F_{P_{0}}$ - Foster's number of calculated probability $\mathrm{P} \%$; $\mathrm{C}_{v}$ - variation coefficient.

The average value of the random component $\left(H_{\eta}\right)$, variation $\left(C_{v}\right)$ and asymmetry $\left(C_{s}\right)$ coefficients are calculated using standard statistics methods. According to the calculated parameters a theoretical curve of probability is plotted. Using a table of random numbers the value of probability $\left(P_{i}\right)$ is modelled. Thus, having limited information, unlimited length time series of lake water levels for a given distribution law can be obtained.

The following methods are used for statistical analysis of time series:

- chronological monthly variation curves and differential integral curves were used for change trend evaluation;

- Student and Fisher criteria were used for the evaluation of the statistical differences of parameters:

$$
\begin{gathered}
t=\frac{\bar{x}-\bar{y}}{\sqrt{n_{x} \cdot \hat{\sigma}_{x}^{2}+n_{y} \cdot \hat{\sigma}_{y}^{2}}} \cdot \sqrt{\frac{n_{x} \cdot n_{y} \cdot\left(n_{x}+n_{y}-2\right)}{n_{x}+n_{y}}} ; \\
F=\frac{\hat{\sigma}_{x}^{2}}{\hat{\sigma}_{y}^{2}}
\end{gathered}
$$

$\bar{x}, \bar{y}$ - sample means; $\hat{\sigma}_{x}^{2}$ and $\hat{\sigma}_{y}^{2}$ - sample variance; $n_{x}$ and $n_{y}$ - sample sizes.

Calculated Student criteria $t$ value and Fisher criteria $F$ value were compared to their critical values for a given significance level $\alpha=5 \%$. If $t>t_{\alpha}$, the hypothesis of statistical difference between two sample means is accepted, and if $\mathrm{F}>\mathrm{F}_{\alpha}$ the hypothesis of statistical difference in the series variation investigated is accepted.

SAF and PAF were used for cyclic recurrence assessment. For a more detailed investigation of the characteristics of the process of amplitude-frequency, spectral analysis is needed. For an indication of characteristic rhythms, analysis of their sustainability or variation in time, the spectral-temporal analysis procedure (STAN) was used. STAN is a spectral analysis in a sliding time window. Size of a time window must be chosen according to the demand for harmonics and to be in the maximum frequency interval of detail required of the actual frequency of the process. If the window is too small, information about low frequencies is lost; if the window is too big, the STAN diagram is over-regulated. The time window is chosen to be 11 years in the studied case.

\section{Results and discussion}

The time pattern of the water level of Belorussian lakes was studied with chronological graphs and difference integral curves. Analysis of annual average water levels of Belorussian lakes shows statistically significant $(95 \%)$ trends in the long-term variation of values. Figure 1 represents a chronological pattern, linear and polynomial of the second degree trends of water levels in the investigated lakes. Figure 1 shows that the water level of Belorussian lakes has complex and ambiguous dynamics. Water level can be increasing globally (Osvejskoe, Lukomskoe, Driviaty, Vilejskoe, Vygonoshanskoe lakes) or locally (Lake Senno), decreasing (Chervonoe) and stable (Naroch). It should be noticed that velocities of the named processes are very different (Table 2) because of the wind regime that was formed on Belorussian territory under current conditions (Loginov and Volchak 2005; Loginov et. al. 2005).

Table 1. Criteria for non-stationarity of the processes and model selection

\begin{tabular}{ccc}
\hline SAF & PAF & Model type \\
\hline Declines exponentially & High value if $\mathrm{T}=1$ only & $(\mathrm{AP}(1))$ autoregression of the first order \\
\hline Sine wave decline or exponential decline & High value if $\mathrm{T}=1 \mathrm{~T}=2$ & $(\mathrm{AP}(2))$ autoregression of the second order \\
\hline High value if $T=1$, other values are zero & $\begin{array}{c}\text { Declines exponentially or oscillates with } \\
\text { the sign change }\end{array}$ & $(\mathrm{CC}(1))$ moving average of the first order \\
\hline $\begin{array}{c}\text { High value if } \mathrm{T}=1 \text { and } \mathrm{T}=2 \text {, other values are zero } \\
\text { (decline is monotonic or oscillating) }\end{array}$ & $\begin{array}{c}\text { Sine wave or exponential decline } \\
\text { Ordinates values exponentially declining or } \\
\text { monotonically oscillating }\end{array}$ & $(\mathrm{APC}(2))$ moving average of the second order \\
\hline
\end{tabular}



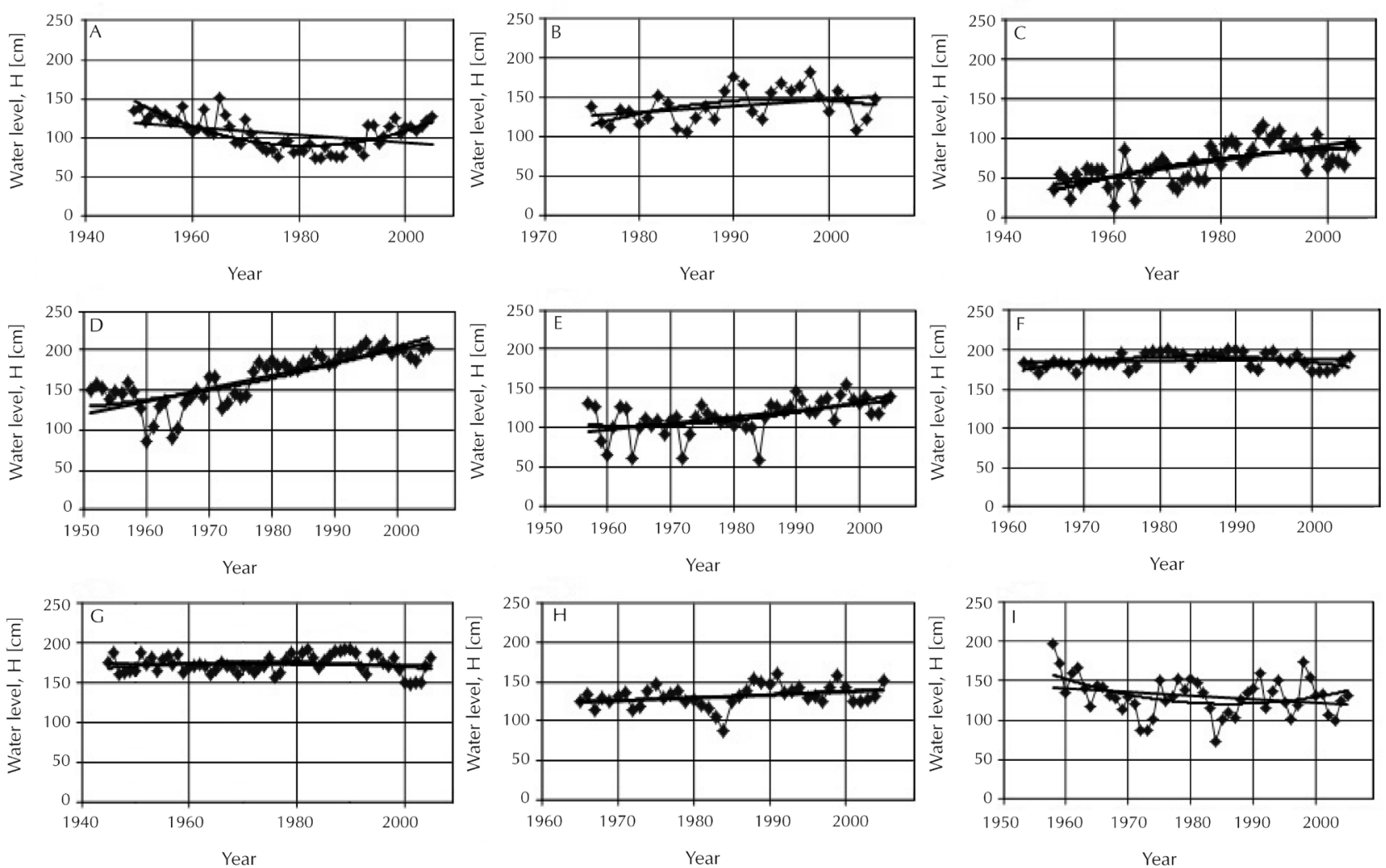

Fig. 1. Chronological pattern of annual average water levels in Belorussian lakes: A - Senno, B - Lukomskoe, C - Neshedro, D - Osvejskoe, E - Driviaty, F - Miastro, G - Naroch, H - Vygonoshanskoe, I - Chervonoe

Table 2. Water level change velocity parameters of Belorussian lakes

\begin{tabular}{lcccccc}
\hline & & \multicolumn{5}{c}{ Models } \\
\cline { 3 - 7 } & \multirow{2}{*}{ Lake } & \multicolumn{2}{c}{ linear (2) } & \multicolumn{3}{c}{ Polinomal (3) } \\
\cline { 3 - 7 } & & \multicolumn{2}{c}{ Coefficients } & Coefficients \\
\cline { 3 - 7 } & & $\begin{array}{c}\text { a, } \\
\text { cm /10 years }\end{array}$ & $R$ & cm /10 years & $b$ & $R$ \\
\hline Senno & $1949-2005$ & -4.8 & $-\mathbf{0 . 3 9}$ & 1.10 & -2179 & $\mathbf{0 . 7 7}$ \\
\hline Lukomskoe & $1975-2005$ & 8.4 & $\mathbf{0 . 3 6}$ & -1.61 & 3216 & $\mathbf{0 . 4 6}$ \\
\hline Neshedro & $1949-2005$ & 9.7 & 0.67 & -0.28 & 553 & 0.69 \\
\hline Osvejskoe & $1951-2005$ & 15.9 & $\mathbf{0 . 8 1}$ & 0.30 & -575 & $\mathbf{0 . 8 1}$ \\
\hline Driviaty & $1957-2005$ & 8.1 & $\mathbf{0 . 5 3}$ & 0.42 & -832 & $\mathbf{0 . 5 5}$ \\
\hline Miastro & $1962-2005$ & 0.85 & 0.12 & -0.65 & 1307 & $\mathbf{0 . 5 4}$ \\
\hline Naroch & $1945-2005$ & -0.15 & 0.00 & -0.17 & 339 & 0.22 \\
\hline Vygonoshanskoe & $1965-2005$ & 3.7 & $\mathbf{0 . 3 2}$ & 0.04 & -82 & $\mathbf{0 . 3 2}$ \\
\hline Chervone & $1958-2005$ & -4.2 & -0.24 & 0.938 & -1861 & $\mathbf{0 . 4 1}$ \\
\hline
\end{tabular}

Note: statistically significant differences are bold 
Empirical probability curves for time series of lakes' water levels for all periods match Pearson distribution of the third type for different combinations $C_{s}=(1-3) C_{v}$.

Application of parametrical criteria for statistic hypothesis approval is valid because the probability distribution function of lakes' water levels is slightly different from normal distribution for such parameters. Histograms plotted for the annual average water levels of lakes shows that distribution is close to normal (Fig. 2).

Analysis of homogeneity of series of evaporation from the water surface - Let us consider the stability of the sample statistics (average, variation coefficient, autocorrelation coefficient) when changing averaging periods for average annual water levels of Belorussian lakes during the period of instrumental observation. Investigated time series were divided into two periods: from the beginning of observations to 1985 inclusive and from 1986 (when average air temperatures started to increase) to 2005. For evaluation of differences in lake water levels statistics Student (sample average evaluation; equation 8) and Fisher's (sample dispersion evaluation; equation 9) criteria were used. Table 4 represents basic statistics parameters for named intervals and also a statistical test for homogeneity results.

Statistically significant differences were found during analysis of sample averages of annual average water levels for Lakes Lukomskoe, Neshedro, Osvejskoe, Driviaty, Vilejskoe and Vygonoshanskoe. Statistically significant variation coefficients were found only for 2 lakes: Osvejskoe and Driviaty. Statistically significant differences for autocorrelation coefficients were observed only for Lake Naroch.

Table 3 represents sample evaluation of basic statistics parameters of time series of annual average water levels in Belorussian lakes during the period of instrumental observations.

Analysis of cyclicity of evaporation from water surface - The concept of cyclicality in long-term lake water level variations should be considered together with the concept of accidentality. Using cycles for the prognosis of lake level regime is complicated because cycles are aperiodical. Phase, amplitude and cycle du-
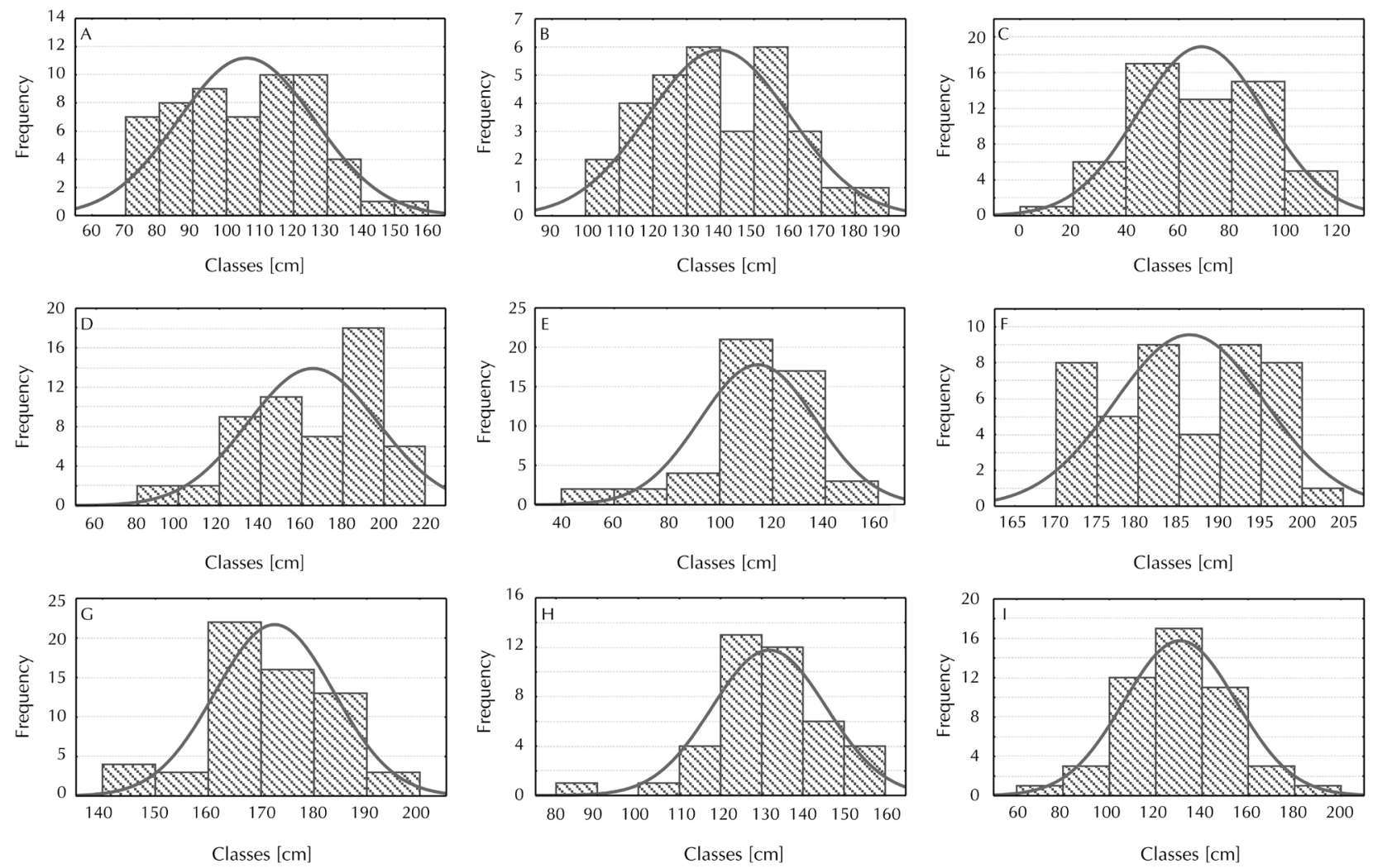

Fig. 2. Histograms of annual average Belorussian lake water level time series distribution: A - Senno, B - Lukomskoe, C - Neshedro, D - Osvejskoe, E - Driviaty, F - Miastro, G - Naroch, H - Vygonoshanskoe, I - Chervonoe 
Table 3. Basic statistics of parameters of the annual average water level of Belorussian lakes during the period of instrumental observations

\begin{tabular}{|c|c|c|c|c|c|}
\hline \multirow{2}{*}{ Lake } & \multirow{2}{*}{ Period } & \multirow{2}{*}{ Avg. water level [cm] } & \multicolumn{3}{|c|}{ Coefficients } \\
\hline & & & Variations & Asymmetry & Autocorrelation \\
\hline Senno & $1949-2005$ & 106 & 0.19 & 0.13 & 0.71 \\
\hline Lukomskoe & $1975-2005$ & 140 & 0.15 & 0.21 & 0.50 \\
\hline Neshedro & 1949-2005 & 69 & 0.35 & -0.09 & 0.69 \\
\hline Osvejskoe & $1951-2005$ & 165 & 0.19 & -0.64 & 0.88 \\
\hline Driviaty & $1957-2005$ & 114 & 0.19 & -0.91 & 0.45 \\
\hline Miastro & $1962-2005$ & 186 & 0.05 & -0.13 & 0.55 \\
\hline Naroch & $1945-2005$ & 173 & 0.06 & -0.26 & 0.52 \\
\hline Vygonoshanskoe & $1965-2005$ & 132 & 0.10 & -0.45 & 0.55 \\
\hline Chervonoe & $1958-2005$ & 131 & 0.18 & 0.13 & 0.53 \\
\hline
\end{tabular}

Table 4. Basic statistics of parameters of the time series of Belorussian lake water levels for different averaging intervals

\begin{tabular}{|c|c|c|c|c|c|}
\hline \multirow{2}{*}{ Lake } & \multirow{2}{*}{ Period } & \multirow{2}{*}{ Avg. water level [cm] } & \multicolumn{3}{|c|}{ Coefficients } \\
\hline & & & Variations & Asymmetry & Autocorrelation \\
\hline \multirow{3}{*}{ Senno } & $1949-1985$ & 108 & 0.20 & 0.14 & 0.72 \\
\hline & $1986-2005$ & 103 & 0.17 & -0.33 & 0.67 \\
\hline & $1949-2005$ & 106 & 0.19 & 0.13 & 0.71 \\
\hline \multirow{3}{*}{ Lukomskoe } & $1975-1985$ & 126 & 0.12 & 0.27 & 0.18 \\
\hline & $1986-2005$ & 147 & 0.14 & -0.14 & 0.38 \\
\hline & $1975-2005$ & 140 & 0.15 & 0.21 & 0.50 \\
\hline \multirow{3}{*}{ Neshedro } & $1949-1985$ & 58 & 0.35 & 0.05 & 0.49 \\
\hline & $1986-2005$ & 89 & 0.18 & -0.09 & 0.48 \\
\hline & $1949-2005$ & 69 & 0.35 & -0.09 & 0.69 \\
\hline \multirow{3}{*}{ Osvejskoe } & $1951-1985$ & 148 & 0.18 & -0.57 & 0.76 \\
\hline & $1986-2005$ & 196 & 0.04 & 0.15 & 0.41 \\
\hline & $1951-2005$ & 165 & 0.19 & -0.64 & 0.88 \\
\hline \multirow{3}{*}{ Driviaty } & $1957-1985$ & 103 & 0.20 & -0.97 & 0.08 \\
\hline & $1986-2005$ & 131 & 0.09 & 0.11 & 0.08 \\
\hline & $1957-2005$ & 114 & 0.19 & -0.91 & 0.45 \\
\hline \multirow{3}{*}{ Miastro } & $1962-1985$ & 185 & 0.05 & 0.03 & 0.45 \\
\hline & $1986-2005$ & 187 & 0.05 & -0.37 & 0.62 \\
\hline & $1962-2005$ & 186 & 0.05 & -0.13 & 0.55 \\
\hline \multirow{3}{*}{ Naroch } & $1945-1985$ & 172 & 0.05 & 0.34 & 0.21 \\
\hline & $1986-2005$ & 173 & 0.09 & -0.60 & 0.74 \\
\hline & $1945-2005$ & 173 & 0.06 & -0.26 & 0.52 \\
\hline \multirow{3}{*}{ Vygonoshanskoe } & $1965-1985$ & 125 & 0.10 & -1.11 & 0.39 \\
\hline & $1986-2005$ & 139 & 0.08 & 0.38 & 0.37 \\
\hline & $1965-2005$ & 132 & 0.10 & -0.45 & 0.55 \\
\hline \multirow{3}{*}{ Chervonoe } & $1958-1985$ & 132 & 0.21 & -0.04 & 0.62 \\
\hline & $1986-2005$ & 129 & 0.16 & 0.48 & 0.31 \\
\hline & $1958-2005$ & 131 & 0.18 & 0.13 & 0.53 \\
\hline
\end{tabular}

Note: statistically significant differences are bold 
ration change have no visible patterns. Besides, there is no consensus about the nature of such cycles because objective methods of identification and analysis of cycles of lake water levels are absent. It is considered that such cycles are caused by external (spacephysical) factors or by self-oscillating processes in the
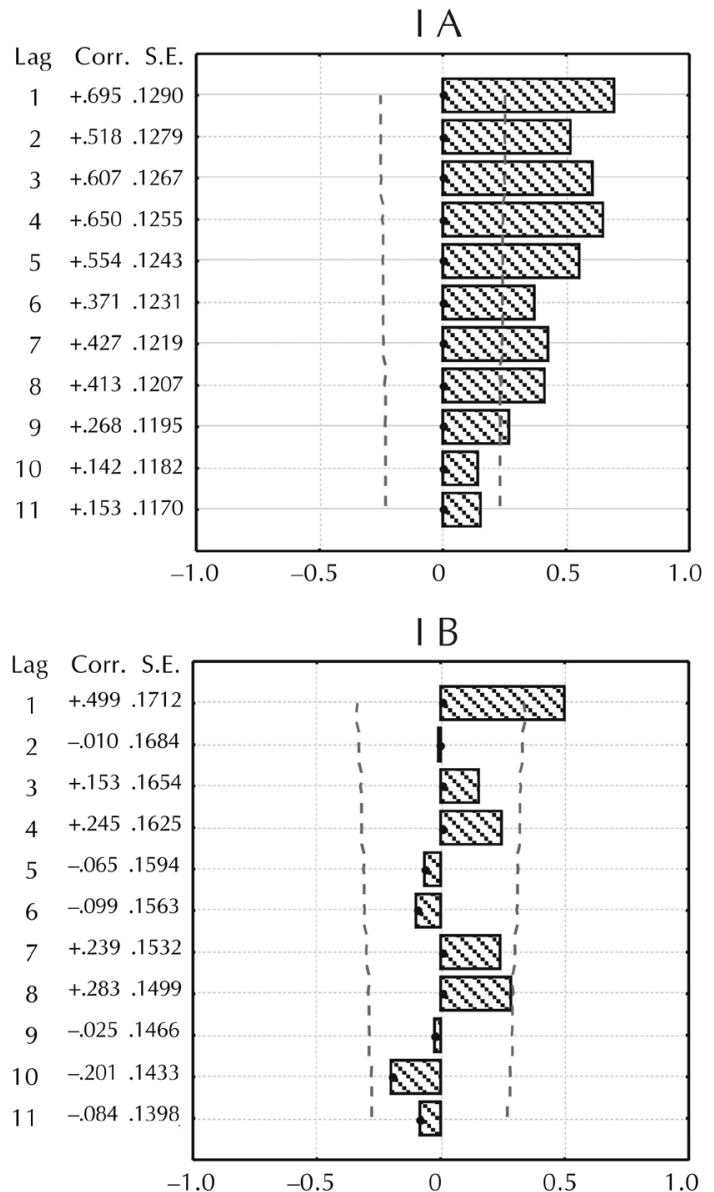

I C

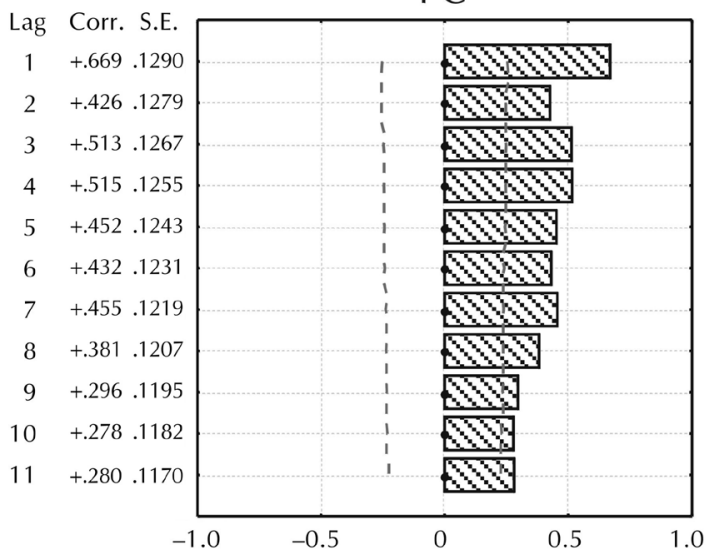

atmosphere-hydrosphere system of the Earth, or by natural characteristics of any random sequence (Bjerring et al. 2013; Li and Morrill 2013; MacKay and Seglenieks 2013).

Figure 3 shows that, according to SAF patterns of annual average lake water level changes, Belorus-
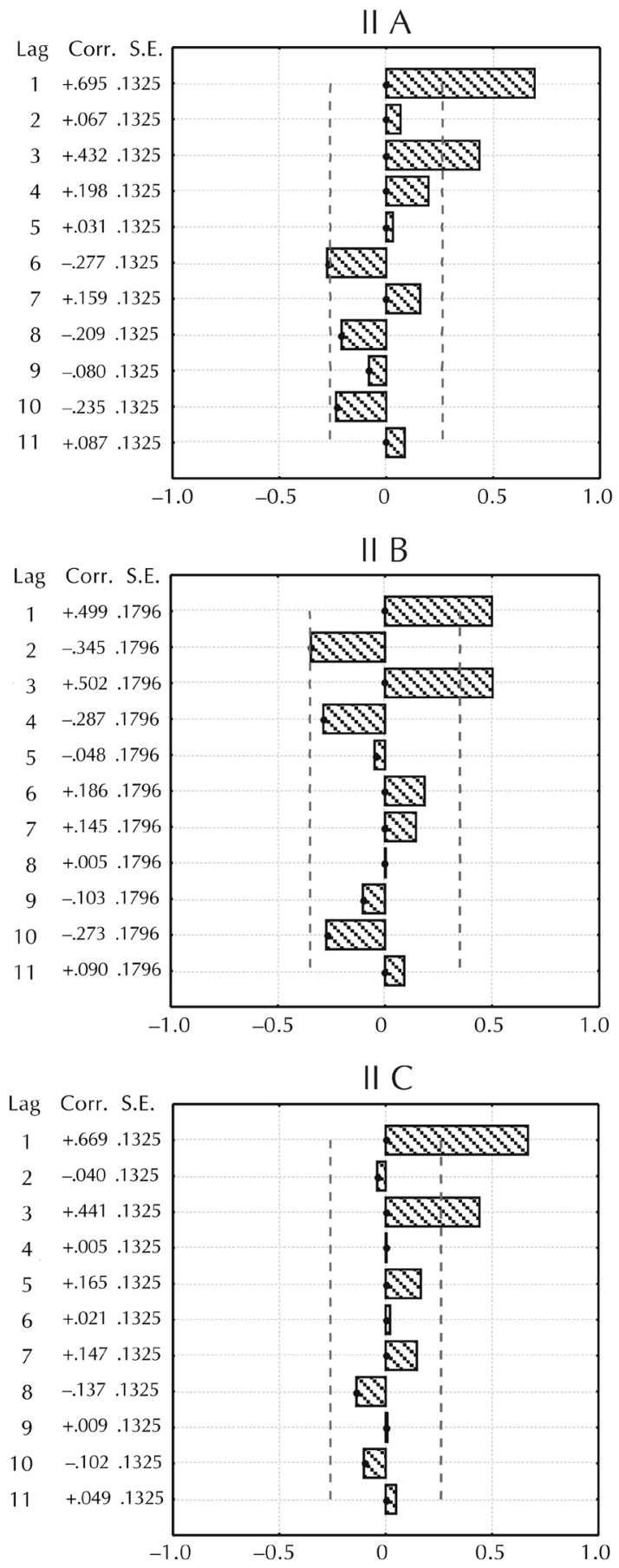

Fig. 3. Autocorrelation function (I) and partial autocorrelation function (II) annual average Belorussian lakes water level: A - Senno, B - Lukomskoe, C - Neshedro, D - Osvejskoe, E - Driviaty, F - Miastro, G - Naroch, H - Vygonoshanskoe, I - Chervonoe 
I D

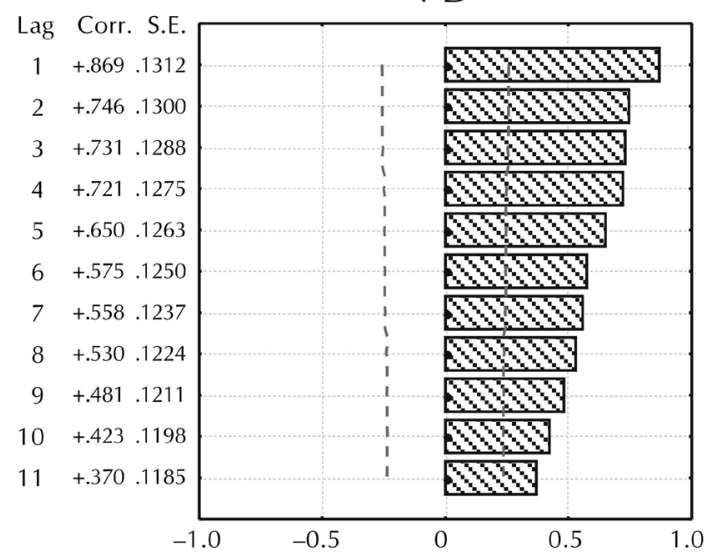

I E

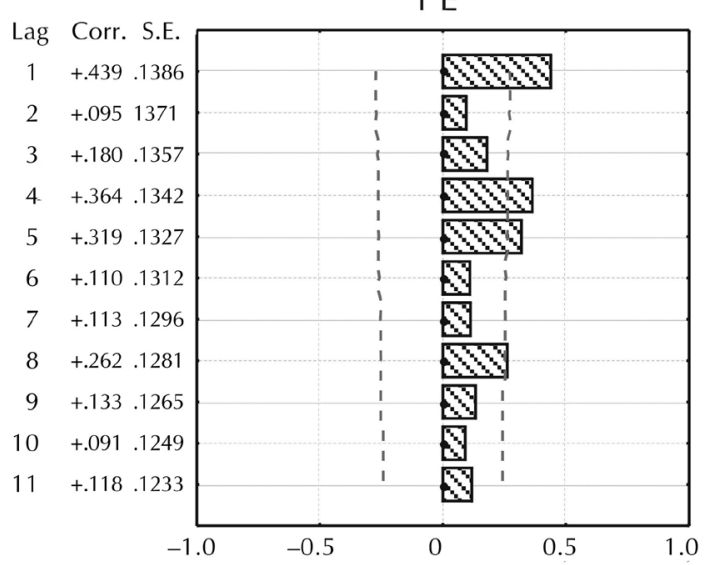

I F

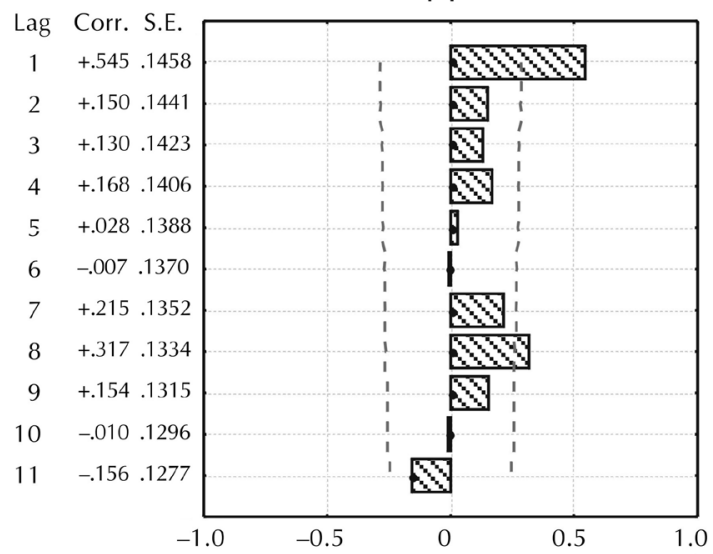

sian lakes can be divided into two groups. For the first lake group (Lukomskoe, Driviaty, Miastro, Naroch, Vygonoshanskoe, Chervonoe) there are statistically significant correlation coefficients for $\tau=1$, while all the other ordinate values are statistically insignificant with rare exceptions. For the second lake group (Senno, Neshedro, Osvejskoe) there are statistically
II D

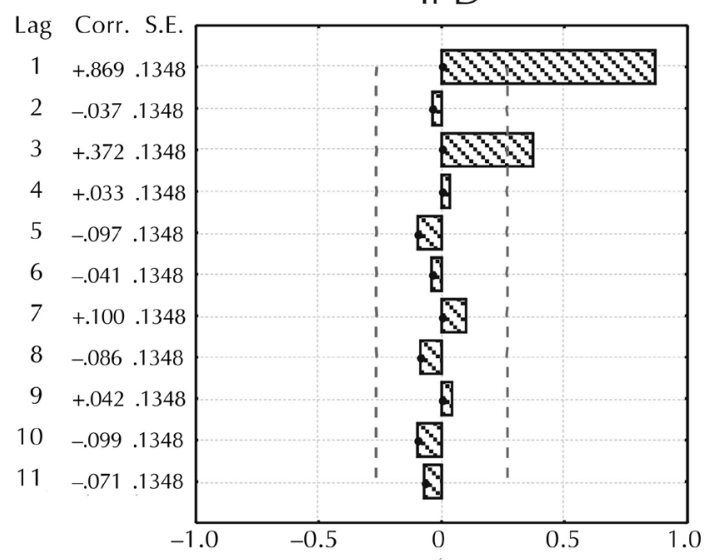

II $E$

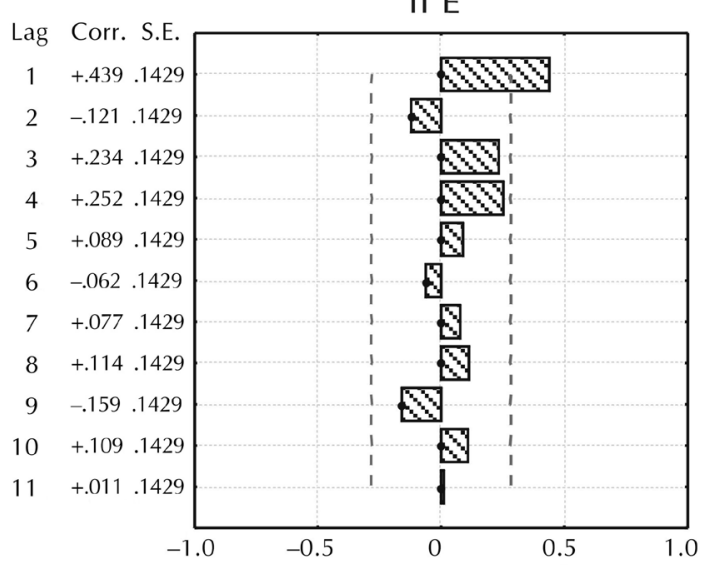

II F

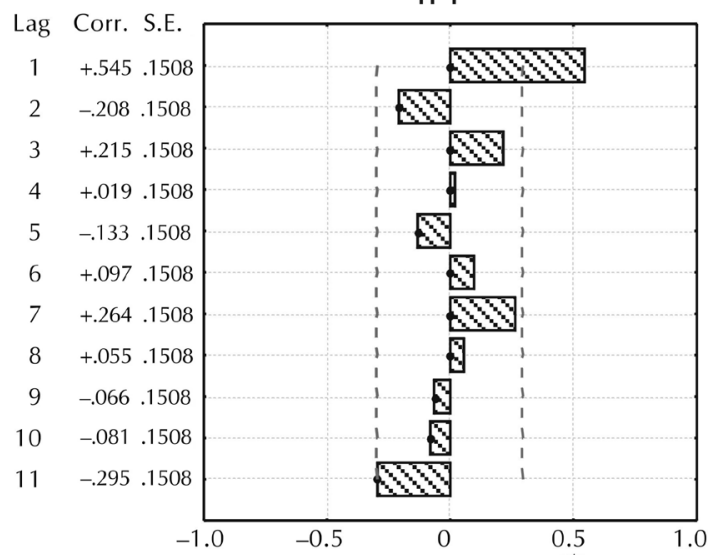

significant correlation coefficients, the values of which gradually decrease with an increase in the time shifts. Analysis of STAN-diagrams of time series of annual average lake water levels shows that 4 and 11year cycles are prevailing, and also that 5 and 6-year cycles are present (Fig. 4). Two short cycles can be identified for Lake Senno: a 4-year one in the period 
I G

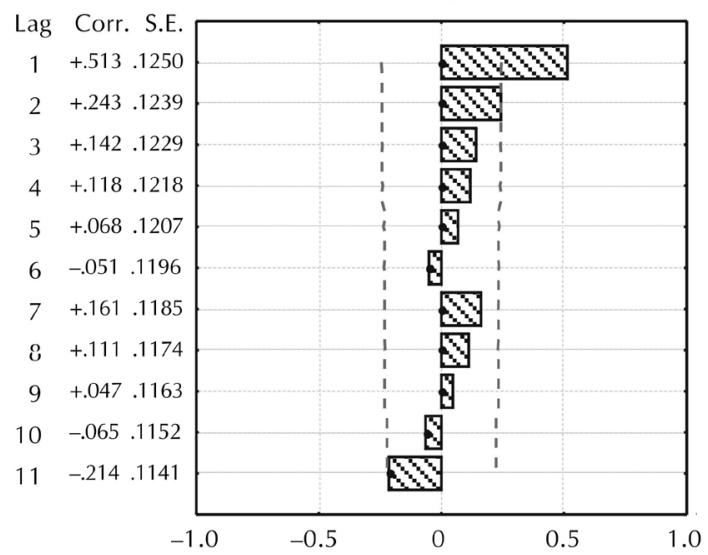

$\mathrm{I} H$

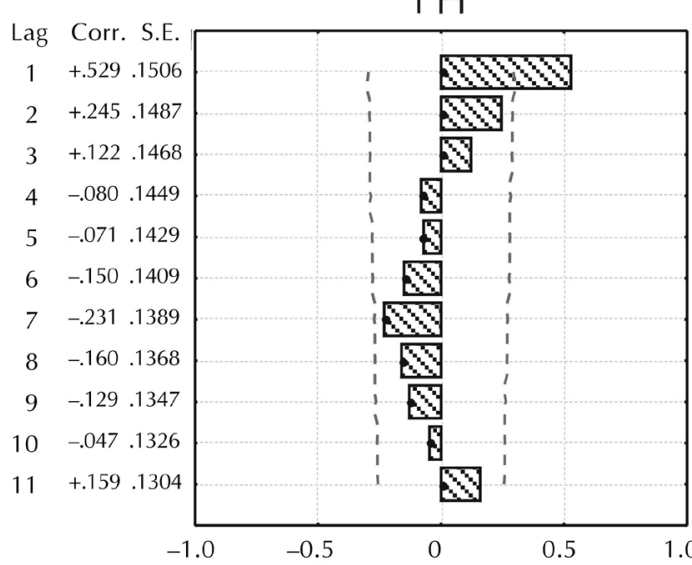

I I

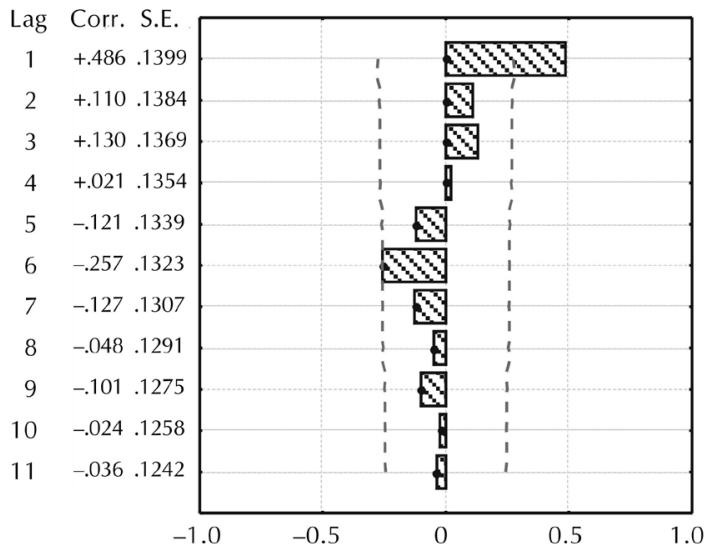

between 1957 and 1968, and a 6-year cycle from 1963 to 1973. For Lake Lukomskoe, except for a 4-year cycle in the period between 1980 and 1988 and a 6-year cycle between 1988 and 1996, an 11-year cycle can be identified during the whole studied period. A five-year cycle was identified for Lake Neshedro in the period between 1958 and 1968. A strong 11-year cycle is typi-
II $G$

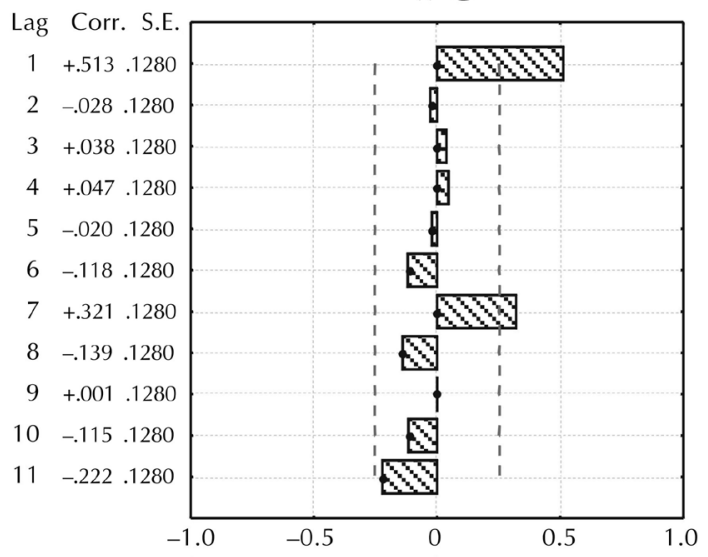

II H

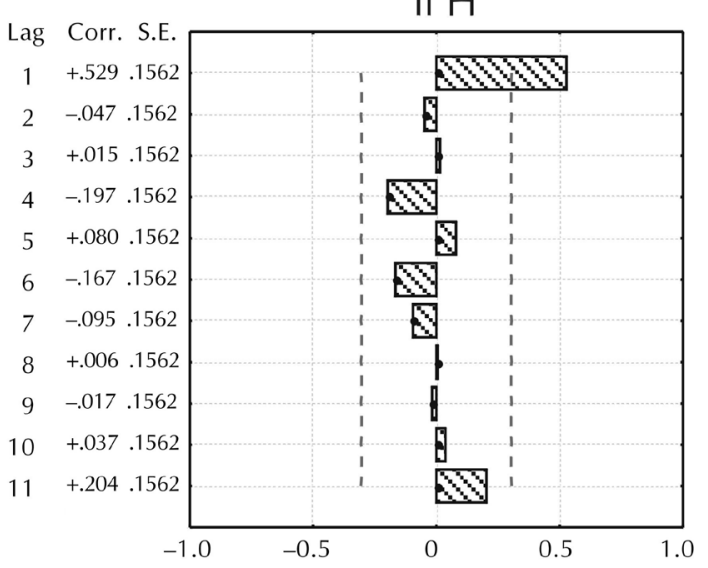

II I

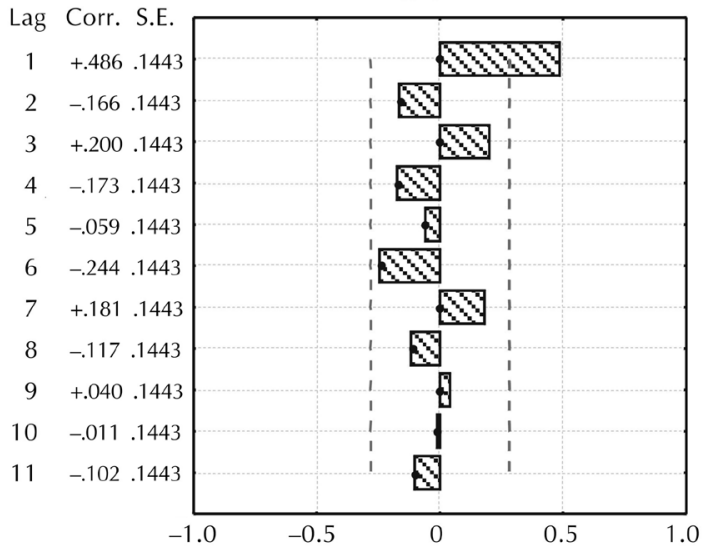

cal for Lake Osvejskoe in the period from 1955 to 1983 and a less powerful 6-year cycle from 1955 to 1965 . No sustainable cycles were identified for Lake Driviaty. A four-year cycle is typical for Lake Miastro in the period from 1975 to 2003. Two cycles were identified for Lake Naroch: a 6-year cycle in the period from 1972 to 2003, and an 11-year cycle from 1977 to 2003. For 

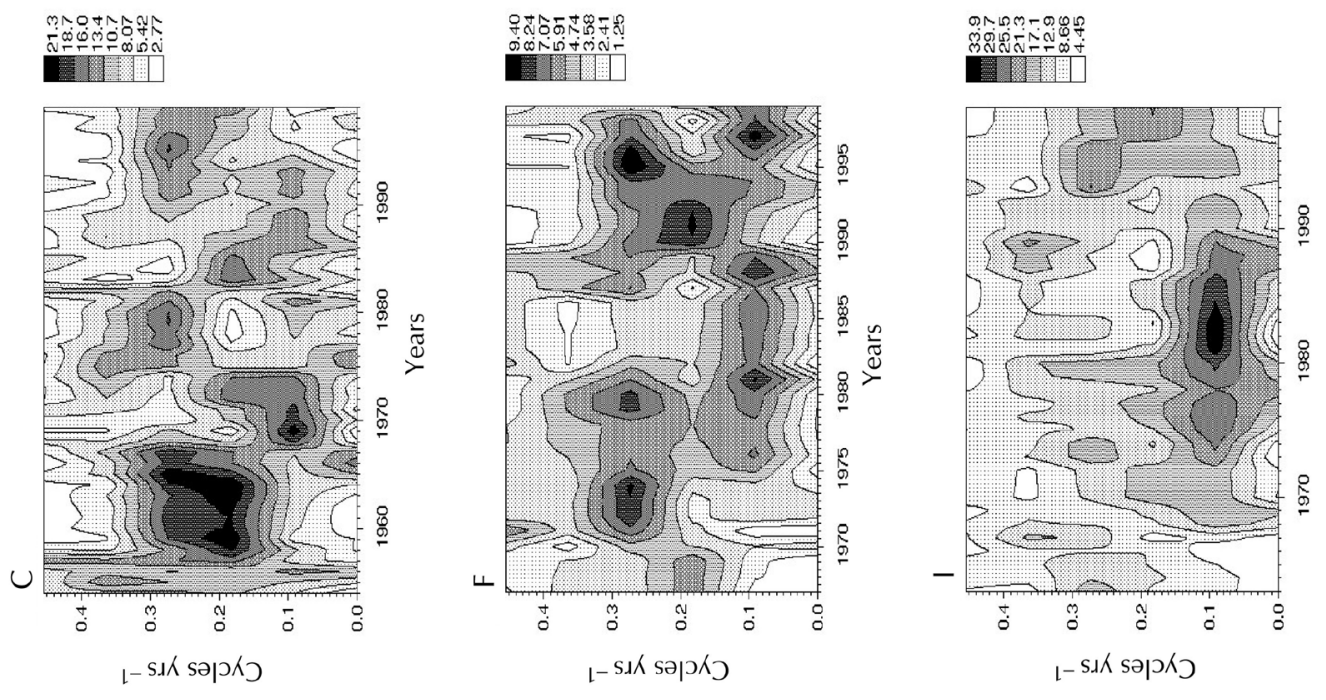

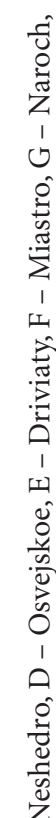
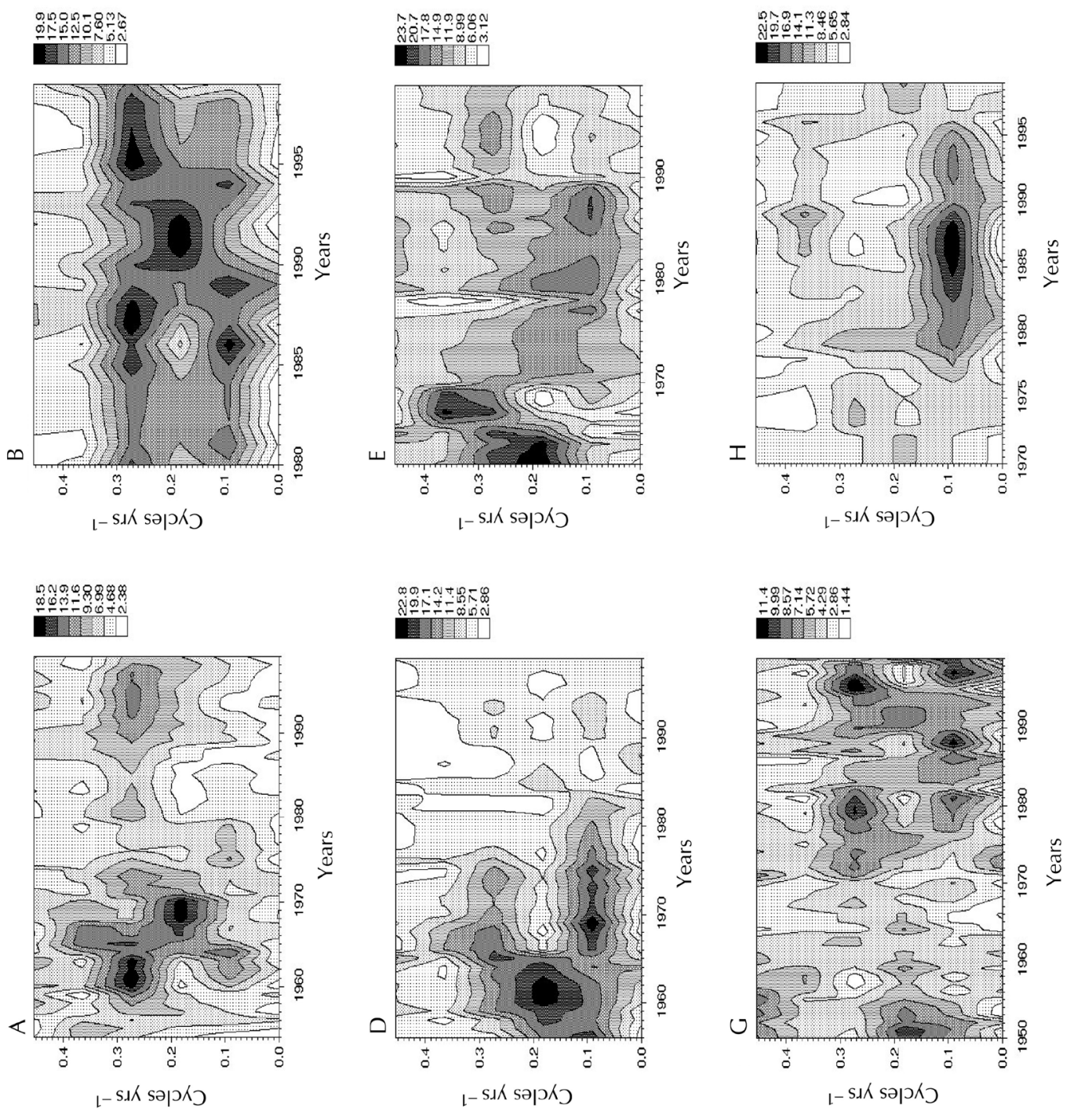
Lakes Vygonoshanskoe and Cervonoe 11-year cycles are typical in periods from 1978 to 1995 and 19671992, respectively.

Practical methods of spectral analysis and identification of hidden periodicities did not succeed (Ratkovich 1976). The weaknesses of such an approach are the cycle's instability and the possibility of physical (genetic) interpretation of cycles. The latter is typical for all methods developed within the statistical concept.

Taking into account that both criteria give comparable results, application of the principle of cyclicity (quasiperiodicity) for long-term prognosis of annual average lake level variation in Belorussian lakes is justified.

Predictive model plotting - Sample SAF and PAF should be considered together for a given process to define variation of the annual average water level if the trend is not explicit. A criterion for the evaluation of the degree of non-stationarity of the processes is used in such cases, and the model is chosen according to data in Table 1.

In the studied case SAF is decreasing exponentially and PAF has significant value for $\tau=1$, while all the other ordinates' values are statistically insignificant and are characterized by alternation of positive and negative values (Fig. 3). Therefore, the studied process of variation of lake water levels may be identified as an autoregression model AP $(\tau)$ :

$$
H(t+1)=H_{c p}+r(1) \cdot\left[H(t)-H_{a v}\right]+\xi(t+1),
$$

$H(t)$ and $H(t-1)$ - water levels in lake $\left[\mathrm{m}^{3} \mathrm{~s}^{-1}\right.$ per $t+1$ and previous $(t)$ years]; $\xi(t)-$ Gaussian „white noise" with zero average $\sigma_{\xi}=\sigma_{H} \cdot \sqrt{1-r(1)}$.
Results of our study of regularities of long-term variations of annual average water levels of Belorussian lakes allow the authors to suggest a firmly established connection between levels of adjacent years. This is the basis to describe the annual average levels of lake water as a simple Markov chain:

$$
H(t+1)=r(1) \cdot H(t)+\xi(t+1)
$$

$H(t+1)$ - water level per predicted year; $H(t)$ previous year's water level; $\xi(t)$ - not dependent on $H_{a v}$ random value.

We made an attempt to describe lake water level variations with a complex Markov model with a shift for 11 years. On the basis of analysis of cyclicity in time series with the help of SAF and PAF we managed to plot a series of predicting models allowing us to evaluate the dynamics of the process one year in advance. Results of regression-correlation analysis are represented in Table 5. Statistically significant models are presented in Table 5. Checking these models on independent material showed their satisfactory convergence (Fig. 5). The models represent regularities in variations of lake water levels and can be used for short-term prognosis.

\section{Conclusions}

The estimation of the degree of uniformity of the characteristics of basic statistics of time series of Belorussian lake water levels during the period of instrumental observations allows us to draw the conclusion that there are statistically significant changes in dynamics of annual average water levels in individual Belorussian lakes that are due to natural climate or anthropogenic changes in the hydrological cycle.

\begin{tabular}{lll}
\hline \multicolumn{1}{c}{ Lake } & \multicolumn{1}{c}{ Model type } & $\mathrm{R}$ \\
\hline Senno & $H(t+1)=20.2+0.475 \cdot H(t)+0.322 \cdot H(t-3)$ & 0.70 \\
\hline Neshedro & $H(t+1)=12.8+0.850 \cdot H(t)-0.585 \cdot H(t-1)+0.567 \cdot H(t-2)$ & 0.80 \\
\hline Osvejskoe & $H(t+1)=19.5+0.831 \cdot H(t)-0.369 \cdot H(t-1)+0.441 \cdot H(t-2)$ & 0.93 \\
\hline Driviaty & $H(t+1)=30.9+0.484 \cdot H(t)+0.306 \cdot H(t-7)$ & 0.60 \\
\hline Miastro & $H(t+1)=45.7+0.462 \cdot H(t)+0.295 \cdot H(t-7)$ & 0.59 \\
\hline Naroch & $H(t+1)=53.8+0.634 \cdot H(t)-0.321 \cdot H(t-5)+0.441 \cdot H(t-6)$ & 0.67 \\
\hline Vygonoshanskoe & $H(t+1)=54.5+0.601 \cdot H(t)$ & 0.59 \\
\hline Chervonoe & $H(t+1)=115.5+0.383 \cdot H(t)-0.298 \cdot H(t-5)$ & 0.55 \\
\hline
\end{tabular}




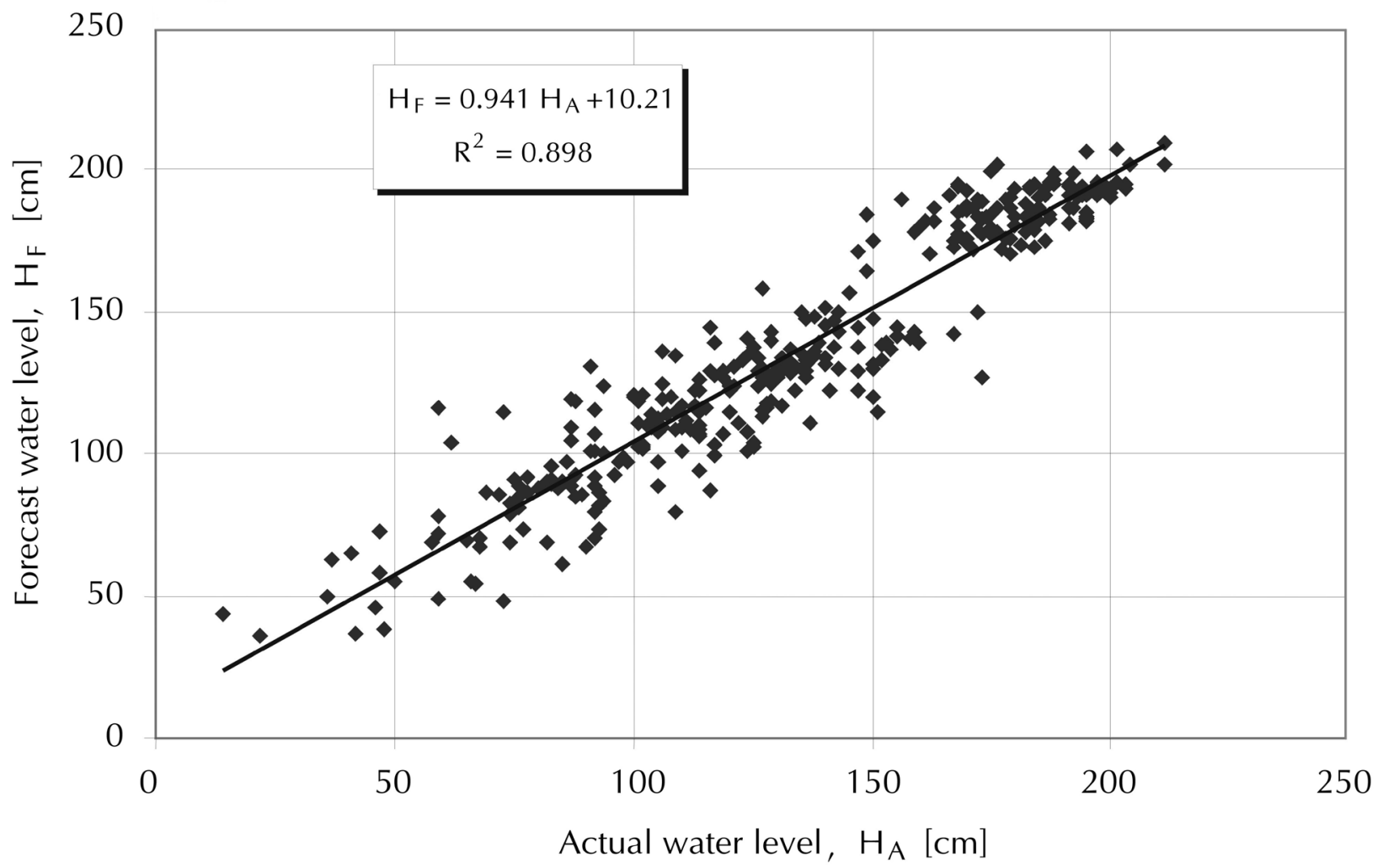

Fig. 5. Actual and forecast lake water levels

Stationarity of the process of long-term lake water levels is typical for individual lakes. When analysing regularities of long-term variations of lake water levels, the method of random processes theory should be used together with analysis of the genesis of the process and its determining natural and economic factors, with climate in the first place.

The possibility of plotting predicting models of lake water levels one year in advance was shown. The complication in plotting predicting models is in its individuality, the huge volume of initial data and the impossibility of immediate assessment of the results. Additional complications are caused by the inhomogeneity of time series of water levels in lakes.

\section{References}

Bjerring R., Olsen J., Jeppesen E., Buchardt B., Heinemeier J., McGowan S., Leavitt P.R., Odgaard B.V., 2013, Climate-driven changes in water level: A decadal scale multi-proxy study recording the 8.2-ka event and ecosystem responses in Lake Sarup (Denmark), J. Paleolimnol. 49(2): 267-285.
Boks D., Dzhenkins G., 1974, Analiz vremiennych riadov, prognoz i upravlienie. Tom 1 (Time series analysis, forecasting and control. Vol. 1), Izd. Mir, Moscov, p. 406 (in Russian).

Ismaiylov G. Kh., Fedorov V.M., 2001, Analysis of long-term variations in the Volga annual runoff), Water Resour. 28(5): 469-477.

Li. Y., Morrill C., 2013, Lake levels in Asia at the Last Glacial Maximum as indicators of hydrologic sensitivity to greenhouse gas concentrations, Quaternary Sci. Rev. 60: 1-12.

Loginov V.F., Volchek A.A., 2005, Izmenenie ispareniia s vodnojpoverkhnosti na teritorii Belarusi (Changes in evaporation from water surface in Belarussia's area), Geografia Prirodnye Resursy 26(2): 137-144 (in Russian, English summary).

Loginov V.F., Volchek A.A., Volobueva G.V., 2005, Izmenenie vetrovogo rezhima na territorii Belarusi v XX v. (The wind regime changes in Belarus in the 20th century), Prirodnye Resursy 10(4): 5-12 (in Belorussian).

MacKay M., Seglenieks F., 2013, On the simulation of Laurentian Great Lakes water levels under projections of global climate change, Climatic Change 117(1-2): 55-67.

Ratkovich D.Ya., 1976, Mnogoletnie kolebaniya rechnogo stoka (The long-term fluctuations of river flow), Gidrometeoizdat, Leningrad, p. 255 (in Russian). 